\title{
An executive chef's insights into hospitality in New Zealand: Brent Martin
}

\section{Tracy Harkison and Brent Martin}

Tracy is programme leader for the Bachelor of International Hospitality Management at Auckland University of Technology. Her research passions are hospitality education and the co-creation of luxury accommodation experiences.

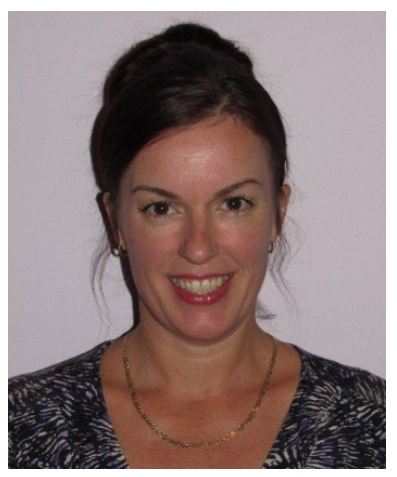

Brent Martin is executive chef at Park Hyatt Auckland. Prior to his time with Hyatt, Brent's extensive career included stints at the Park Royal in Wellington, Sheraton on the Park in Sydney and the Waldorf in London.

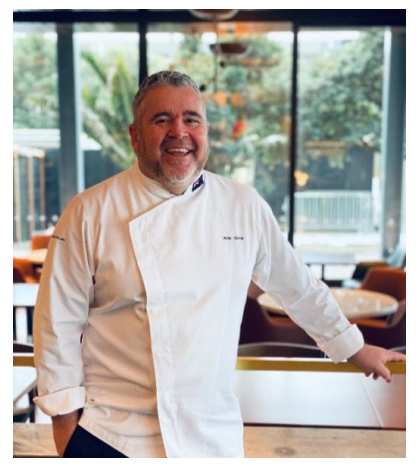

2020 was one of the most challenging years to date for the New Zealand hospitality industry. As part of a wider study, a series of interviews were conducted to gain insights into what New Zealand professionals faced through this challenging time with some of their philosophical and career overviews. In this second interview, conducted in November 2020, Tracy Harkison interviewed Brent Martin, executive chef at Park Hyatt Auckland. Questions asked ranged from his passion for hospitality and dealing with COVID-19 to his hopes for the future of hospitality in New Zealand.

\section{Tracy Harkison}

What do you love about working in hospitality?

\section{Brent Martin}

The biggest thing for me is the opportunity - the opportunities that hospitality has given me. I don't think there is another career that could have given me these opportunities to travel, to live in different cultures, meet different people, and just experience the world. You adapt a lot more and you learn a lot more about your own personality and your own way to deal with things in different cultures. I think hospitality work is a way to broaden people's lives.

\section{Tracy}

Are there unique aspects to the New Zealand hospitality industry?

\section{Brent}

We are an international brand and hopefully this brings a wealth of knowledge back to New Zealand, which we're starting to see - not just in hotels but restaurants who have had several really well-known chefs coming back. So the uniqueness of New Zealand is that we have a clean slate and a blank canvas on which we can create these experiences.

\section{Tracy}

Why start a career in hospitality?

\section{Brent}

There are a couple of components to this, it's the camaraderie and it's the family values that people have. I've been in the industry 30 plus years and the friends that I've gained along the way are my friends for life. The time that you spend working in hospitality is sometimes time spent with your best friend. People that come into hospitality really learn about that. Once those borders open, we're going to be inundated with hundreds of thousands of people coming to New 
Zealand, and this is going to be very much an ongoing process in New Zealand. New Zealand is struggling for hospitality people and it's going to open up a lot of doors for people who may have different views of what hospitality is.

Tracy

When starting in the industry, what advice would you give?

\section{Brent}

You've got to come into the industry with an open mind. You need to have passion and you've got to understand the unsociable hours. But the rewards at the end of what can happen here are amazing. The reward of seeing people eating in your restaurant, eating your food, it is amazing. When somebody comes up to you and says, "That's the best meal I've ever had", it's instant gratification, whereas a lot of people won't be able to get that kind of gratification from a job.

\section{Tracy}

What has been your greatest leadership challenge?

\section{Brent}

The biggest challenge for me was opening a mega-resort in the Bahamas where I had to find 400 plus cooks/staff from a population of about 200,000. So, the biggest challenge for me was to find cooks who could actually cook. To open up this mega-resort with 26 different restaurants with different cuisines and different styles, there were days I thought I'd never get there, but I ended up with over 420 staff members by the time I left the property.

\section{Tracy}

The COVID 19 situation - what was your decision-making process?

\section{Brent}

The biggest thing for us was that we never wanted to lose an employee, and that was our commitment from day one: how do we keep every employee employed in this hotel throughout this pandemic? The team really focused on watching out for each other, helping each other and knowing what the end goal was. But we had to set a standard of what this hotel was going to be; the expectations of the owner, ourselves and obviously the public was the biggest hurdle that we had to really push. We have proper practices throughout the hotel - all the staff wear face masks; that is a corporate directive from our Hyatt Corporation.

\section{Tracy}

How would you change the New Zealand hospitality industry?

\section{Brent}

I wish that we had a lot more energy to be willing to service a guest right. We talk about hospitality in New Zealand and we're very open - you're a family house to guests, which is amazing. It's a refinement of what hospitality could be in New Zealand that is needed. It's the boundaries of how my service is... how involved am I with that person at a table; at the front desk, am I too overpowering, or am I attentive enough. So it's just refining that level of service to really understand who that customer is, and the ability to read the situation that you're in and have three or four talking points. The most important thing 
is, how do we start a conversation and how do we stop a conversation with a customer; it's the hardest thing to do, but it's important.

\section{Corresponding author}

Tracy Harkison can be contacted at: tracy.harkison@aut.ac.nz 